\title{
Power Electronic Converters for Single-Phase Grid Connected Photovoltaic System: An Overview
}

\author{
Ghulam Mustafa Shoro" $^{*}$, D. M. Akbar Hussain ${ }^{2}$ \\ ${ }^{1}$ Institute of Information and Communication Technology, \\ University of Sindh, Jamshoro, 76000, PAKISTAN \\ ${ }^{2}$ Institute of Energy Technology, \\ Aalborg University, Esbjerg Campus, 6700, DENMARK \\ *Corresponding Author
}

DOI: https://doi.org/10.30880/ijie.2020.12.06.028

Received 20 February 2020; Accepted 19 July 2020; Available online 30 July 2020

\begin{abstract}
The Solar photovoltaic (PV) power system have achieved meteoric rise through the years. The uptake is not difficult to explain - a drop in cost of PV systems and spiraling electricity cost, have encouraged the end-user to lessen their bills by producing cheaper electricity and can generate revenue by feeding excess power back to the grid. The solar $\mathrm{PV}$ is intermittent in nature so it dependent on irradiance and ambient temperature. Power electronics technologies plays an important part for optimizing the energy harvesting from PV system. In order to get maximum extracted power and ensure the load is supplied with a good quality voltage, different dc-dc converters topologies and inverters configurations are used. This paper provides an overview of PV inverter configurations and DC-DC topologies to offer a useful insight and reference point for the researchers working in the field of photovoltaic system.
\end{abstract}

Keywords: PV Inverter structures, PV Inverter Configurations, DC-DC Converters, DC-DC Topologies

\section{Introduction}

Solar PV has become the world's fastest-growing energy technology and becoming a major source of power globally. PV has more significant impact upon energy use, demand for solar PV is spreading and expanding as it becomes the most feasible option for electricity generation for powering homes, businesses and utility grids across nations. Photovoltaic generation is clean, silent, free of emissions of greenhouse gases (CO2, NOX) and toxic gases (SO2) [1]. Thus, these advantages are major drivers for increasing penetration degree of solar PV system and make it more and more popular for residential and commercial use. According to Fig. 1, PV industry has experienced 2018 an historic year in which the global PV cumulative installed capacity passed the 505-gigawatt (GW) mark [2]. Only in 2018, global market for surpassed the $100 \mathrm{GW}$ level (including off- grid and on-grid capacity).

Due to intermittent nature of solar PV the output power is unregulated that cannot be used directly by the loads. The rational use of photovoltaic generators is not possible without the use of power electronic converters. Power electronics is the key for power conditioning of renewable energies [3]-[5]. Power converters are used to increase the energy harvest when such cases of shadowing, over current, over voltages, short circuits, and other unpredicted phenomena occurred in PV installations. 


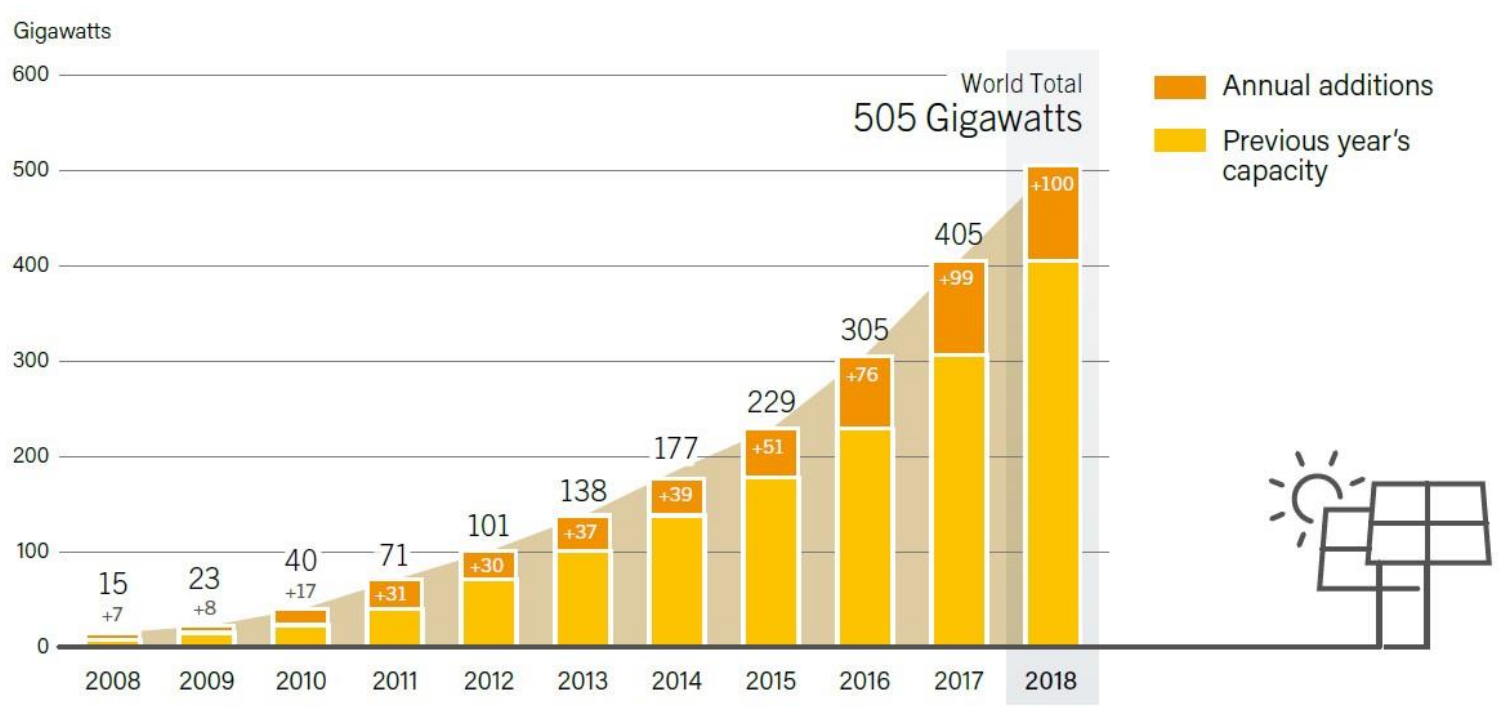

Fig. 1- Solar PV Global Capacity and meteoric rise through the years 2008-2018

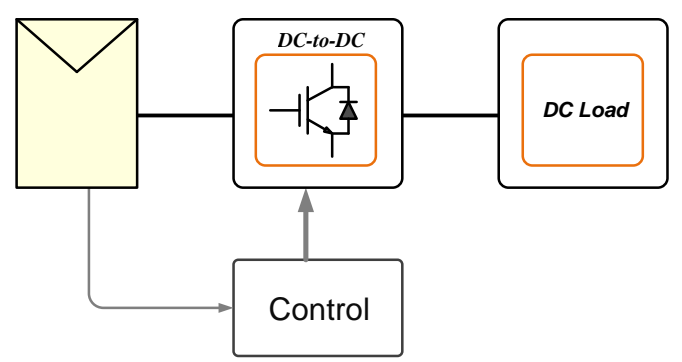

a) PV System with DC-DC Converter

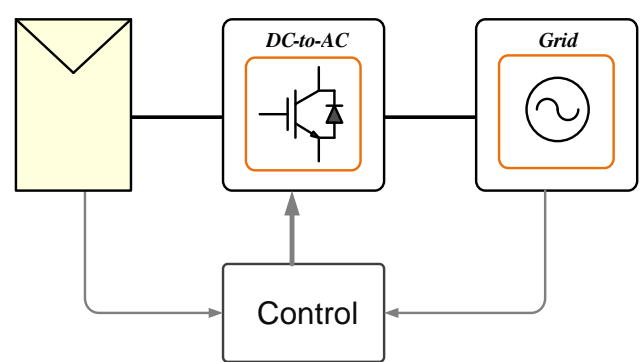

b) Single Stage Grid Connected PV Inverter Configuration

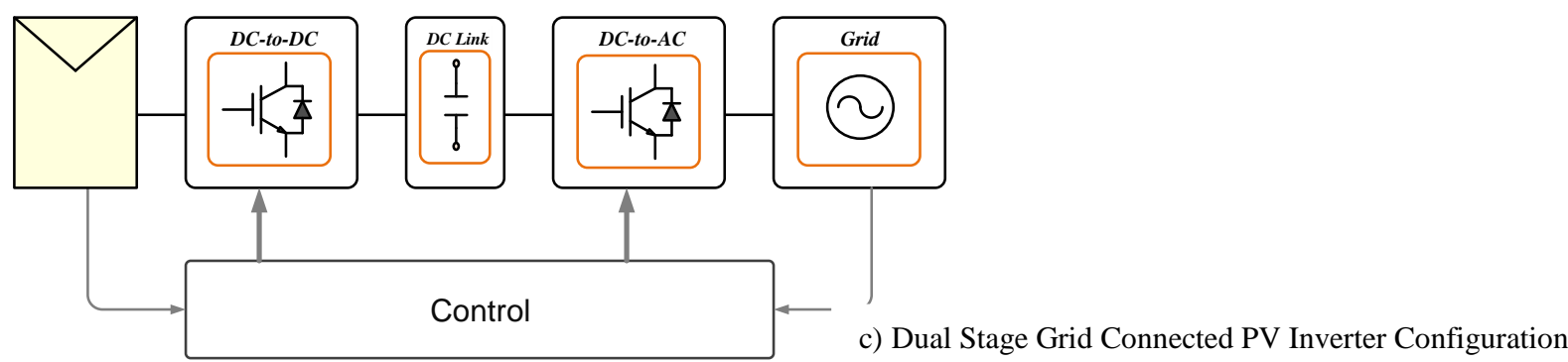

Fig. 2- Photovoltaic System

The role of power converters in photovoltaic system can be categorized either $\mathrm{dc}-\mathrm{dc}$ conversion or dc-ac conversion, as given in Fig. 2 that shows the classification of PV inverters. The choppers are used to track maximum power and maintain the desirable DC voltage for the inverter in photovoltaic system. Inverters are power converters that converters direct current (DC) to alternating current (AC). The researcher and designer are focusing on two areas, first is to improve the efficiency, scalability in capacity of present string/central inverter. This approach moved them toward centralized inverters, for example, SMA's new sunny central 250-800 kW PV inverter and the second is to head for distributed architectures, such as dc-dc optimizers and micro-inverters. 


\section{Photovoltaic Inverter Configuration}

Photovoltaic inverter configurations can be classified into conventional PV inverter structures and decentralized / distributed PV inverter structures. The selection of the right inverter configuration will depend on the application, which decides the size and capacity of PV system that changes generally from several Kilo Watts to 100 Mega Watts level. The given Fig. 3 shows the classification of PV inverters.

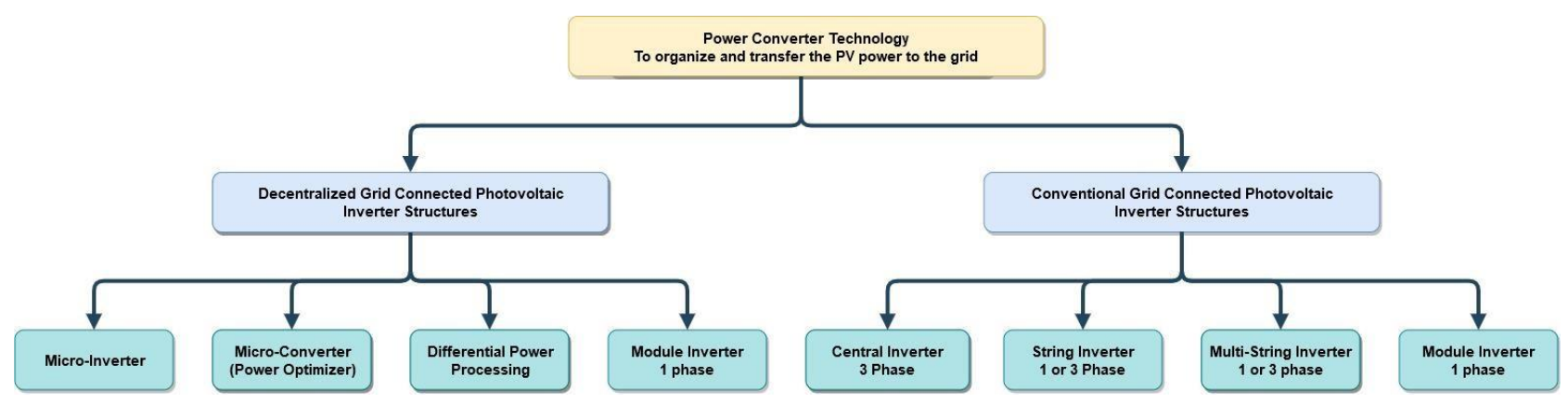

Fig. 3 - Classification of PV Inverters

\subsection{Conventional Grid-Connected Photovoltaic Inverter Structures}

The classification of PV inverter structures are given in Fig. 3. Over the years conventional inverters remained the part of photovoltaic systems. These PV inverters are used for mainly two reasons: to invert and amplify the generated DC power into AC power for the grid and to control PV module using maximum power point tracking (MPPT) to increase energy harvest.

\subsubsection{Central Inverter}

A central inverter is high capacity inverter designed for use with large scale power applications. It is designed to handle more power e.g. $750 \mathrm{~kW} \mathrm{SMA} \mathrm{Central} \mathrm{Inverter} \mathrm{[6].} \mathrm{In} \mathrm{the} \mathrm{architecture} \mathrm{given} \mathrm{in} \mathrm{Fig.} \mathrm{4(a),} \mathrm{the} \mathrm{MPPT} \mathrm{enabled}$ central inverter is connected with parallel PV strings and those PV strings are formed by connecting PV panels in series to create sufficiently high voltages. The role of central MPPT is used to drive all PV modules at same current. The centralized inverter transports the energy from PV generator to the grid and performs several tasks such as grid side current control, voltage amplification and MPPT. The centralized inverter configuration has several advantages such as easier design and implementation, simple maintenance, high efficiency with low cost per KW. There are some drawbacks of this configuration, which are, losses in the string diodes, inability to fix mismatch losses between PV modules, higher cost of DC cable between strings and the inverter, and non-flexible design. Due to a centralized MPPT control, the overall efficiency of the PV power generation is reduced, and power losses are normally higher when compared with string inverter mainly due to partial shading and module mismatching conditions [7]. The stability of the PV plant becomes vulnerable owing to reliance of power generation solely on central inverter. If central inverter malfunctioned the whole PV plant will become out of operation [7], [8].

\subsubsection{String Inverter}

A string inverter is smaller form of centralized inverter, where instead of single inverter, several are employed in the PV plant. The PV plant array can be divided into multiple parallel strings (series of solar panels) and an inverter is assigned to each string as given in Fig. (4b). String inverter has one separate MPPT for each PV string [8]. The string inverter is designed for smaller PV systems up to $10 \mathrm{~kW}$ [9] to serve residential and commercial photovoltaic installations. This configuration has many advantages over central inverter configuration such as improved yield due to separate MPPTs, no power losses in strings (no diodes needed), scalability for future expansion by adding parallel strings, short DC wire, monitoring at string level and lower price because of the mass production. Addition of more PV panels in a string increases the open circuit voltage (Voc) up to required level. The normal operational voltage range is $450-510 \mathrm{~V}$ [10]. Although, the use of multiple MPPT inputs in the inverter allows an increase in the energy yield but problem persists as in central inverter, the efficiency decreases due to partial shadowing and module mismatch losses. Yet, installation requires special racking for the inverter for each string, the extra inverter not only raise the cost of the PV system but also adds power conversion losses.

\subsubsection{Multi-String Inverter}

The multi-string inverter configuration as given in Fig. (4c) is an evolution of the string inverter where instead of inverter, several dc-dc converters are employed in the PV plant. The multi-string inverter is designed for smaller PV 
system for below $10 \mathrm{~kW}$ power levels [8] to serve residential and commercial photovoltaic installations. In this configuration, each dc-dc converters has dedicated MPPT which enhances the energy yield of string and the output of $\mathrm{dc}-\mathrm{dc}$ converters are connected to main inverter through high voltage DC bus. The DC bus streamlines diverse PV module integration and cuts the inverter functionalities, such as transfer of MPPT from Inverters to the dc-dc converters. The multi-string power plant may begin with few modules and later can expands as per the advancement of the load. The multi-string inverters deliver an input voltages somewhere in the range of 125 and $750 \mathrm{~V}$ which gives the flexibility to the user to design of the PV system within that range [11]. Although multistring configuration increases the energy yield of the system at the cost of two power conversion stages that could increase the cost of system.

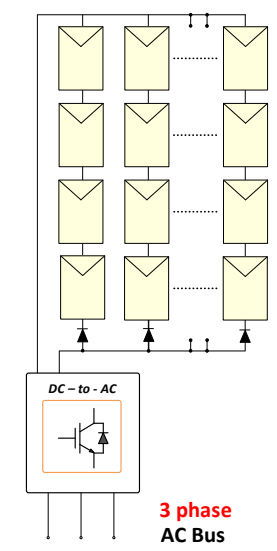

a) Central

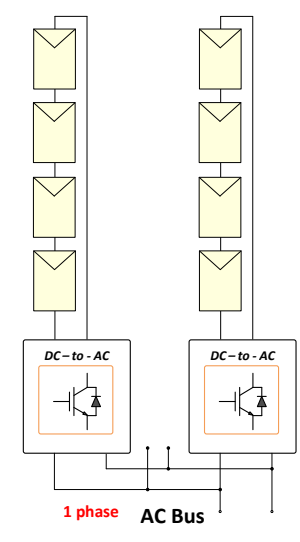

b) String

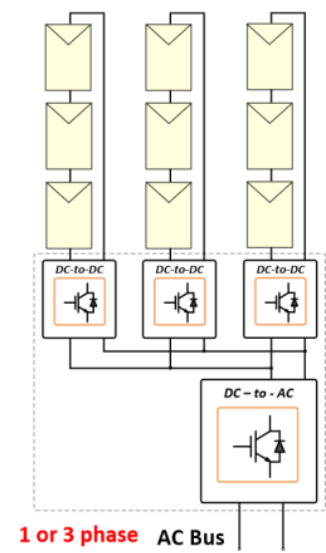

c) Multi-String

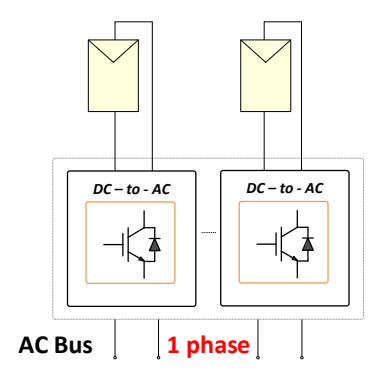

d) AC Module

Fig. 4 - Conventional grid-connected PV inverter stuctures

\subsubsection{AC Module}

AC modules are small scale inverters for integration of photovoltaic modules. In this configuration as given in Fig (4d), every PV module is connected to an inverter mounted on to back of PV module. These individual modules (up to $48 \mathrm{~V}$ and 500 Watts) are prepared to be connected to the load directly or to the single-phase main grid [9]. There is no need for bypass diodes in AC modules; they work independently, if one module fails, the other AC modules will keep on delivering power to the standalone system or main grid. The advantage of AC Module is that every module integrates an inverters and MPPT that maximize power harvest as compared to string inverters. Modular approach of AC module eliminates DC ground fault protection and safety equipment, balance-of-system equipment, string combiners, switches, connectors, fuses, conductors etc. leads to reduction in cost and easy installation, expansion, and maintenance of the whole system saves labor costs and these factors reduces the overall cost of energy. AC module has compact DC system layout that reduces lightning induced surge voltages [12]. AC modules have some disadvantages, like an increased thermal stress on the inverter (PV modules heat up considerably during the day), which shortens the component's lifetime. Difficult maintenance as the inverters are fixed on the back of PV modules, if the inverter fails, repairing or replacing it involves removing the module from the array to access the inverter behind it. AC module structure has not been implemented in medium-scale PV systems [13] because AC modules are use in low power applications.

\subsection{Distributed Grid-Connected Photovoltaic Inverter Structures}

Conventional inverter configurations have certain limitations regarding cost and efficiency. The concept of AC module paved the way of to find new dimensions in the PV systems. The researchers and designers have explored and developed the new concept of module integrated converter (MIC), which emerged as a promising technique in the field of solar PV systems. In order to mitigate the power losses due to series string problems, distributed approach incorporated in the PV system. The distributed approach is moving power electronics into the PV module-level and it is gaining popularity as the technology advances.

\subsubsection{Module Integrated Inverter (MII or Microinverter)}

A MII is an inverter as given in Fig. (5a) mounted on to back of PV module mostly used in residential and commercial solar installations. The power conversion is on per-module basis that make microinverter useful, so every PV module in the installation has separate inverter that contain an independent MPPT that removes the mismatch losses between PV modules. If any PV module is in under shades that can affect only its own output power the other PV modules will keep delivering power to the standalone system or main grid. Owing to MII's modular structure multiple orientations of panels are possible; this approach increases overall energy capture. The disadvantages associated with microinverters 
are decrease in efficiency and increased cost. Microinverter contained PV module can be installed on rooftop, so the heat can reduce its lifetime and due to long successions at 240 volts of AC power, the voltage drops in microinverter is greater when compared with higher voltage DC wiring associated with central inverters.

Table 1 - Summary of Inverter Types and Characteristics

\begin{tabular}{|c|c|c|c|c|}
\hline Inverter Type & AC Module & String & Multi-string & Central \\
\hline Power Range & $100-300 \mathrm{~W}$ & $1000-10,000 \mathrm{~W}$ & $10,000-30,000 \mathrm{~W}$ & $30,000 \mathrm{~W} \sim$ \\
\hline MPPT & yes & yes & Multiple & Multiple \\
\hline Efficiency & $95 \%$ & $93-97 \%$ & $97 \%$ & $97 \%$ \\
\hline DC Bus & $\begin{array}{l}\text { Low Voltage, } \\
\text { Low Current }\end{array}$ & \multicolumn{2}{|c|}{ High Voltage, Low Current } & High Voltage, High Current \\
\hline Phase & 1 Phase & 1 or 3 Phase & 1 or 3 Phase & 3 Phase \\
\hline Applications & Small System & Residential & $\begin{array}{l}\text { Commercial / } \\
\text { Residential }\end{array}$ & $\begin{array}{c}\text { Commercial / Utility scale PV } \\
\text { Plant }\end{array}$ \\
\hline Advantages & $\begin{array}{l}\text { No mismatch losses, } \\
\text { Individual MPPT, No DC } \\
\text { cabling, Flexible design, } \\
\text { easy to add more modules }\end{array}$ & $\begin{array}{l}\text { Readily } \\
\text { Available }\end{array}$ & $\begin{array}{l}\text { Separate MPPT's for } \\
\text { each string, } \\
\text { Readily Available }\end{array}$ & $\begin{array}{l}\text { Lower } \$ / \mathrm{W} \text {; one location for } \\
\text { maintenance }\end{array}$ \\
\hline Disadvantages & $\begin{array}{l}\text { Higher Installation Cost, } \\
\text { replacing a faculty } \\
\text { inverter can be difficult }\end{array}$ & $\begin{array}{l}\text { Only One } \\
\text { MPPT }\end{array}$ & & $\begin{array}{l}\text { High Power losses, mismatch } \\
\text { losses, Inflexible Design, High } \\
\text { Current Harmonics, Low } \\
\text { Power Quality, } \\
\text { No redundancy if inverter fails }\end{array}$ \\
\hline
\end{tabular}

\subsection{Distributed Grid-Connected Photovoltaic Inverter Structures}

Conventional inverter configurations have certain limitations regarding cost and efficiency. The concept of AC module paved the way of to find new dimensions in the PV systems. The researchers and designers have explored and developed the new concept of module integrated converter (MIC), which emerged as a promising technique in the field of solar PV systems. In order to mitigate the power losses due to series string problems, distributed approach incorporated in the PV system. The distributed approach is moving power electronics into the PV module-level and it is gaining popularity as the technology advances.

\subsubsection{Module Integrated Inverter (MII or Microinverter)}

A MII is an inverter as given in fig.(5a) mounted on to back of PV module mostly used in residential and commercial solar installations. The power conversion is on per-module basis that make microinverter useful, so every PV module in the installation has separate inverter that contain an independent MPPT that removes the mismatch losses between PV modules. If any PV module is in under shades that can affect only its own output power the other PV modules will keep delivering power to the standalone system or main grid. Owing to MII's modular structure multiple orientations of panels are possible; this approach increases overall energy capture. The disadvantages associated with microinverters are decrease in efficiency and increased cost. Microinverter contained PV module can be installed on rooftop, so the heat can reduce its lifetime and due to long successions at 240 volts of AC power, the voltage drops in microinverter is greater when compared with higher voltage DC wiring associated with central inverters.

\subsubsection{Module Integrated Converter (Power Optimizer)}

A MIC is PV module integrated with choppers mounted on to back of PV module mostly used in residential and commercial solar installations. The power conversion is on a per-module basis that makes MIC useful so every PV module in the installation has separate dc-dc converters [14] with independent MPPT [15] and output of each MIC is connected in cascade. The MIC perform MPP tracking at the module level, this eliminates mismatches losses. Each module operates at its individual optimal current and voltage, if any PV module is in under shades that can affect only its own output power the other PV modules will keep delivering power to the standalone system or main grid. The cascaded MIC architecture as given in fig. (5b) offers many advantages, it can be used with DC-AC conversion or without DC-AC conversion. This approach improves energy harvest of overall system. When dc-dc converter process power, it introduces insertion loses, even under no mismatch conditions. 


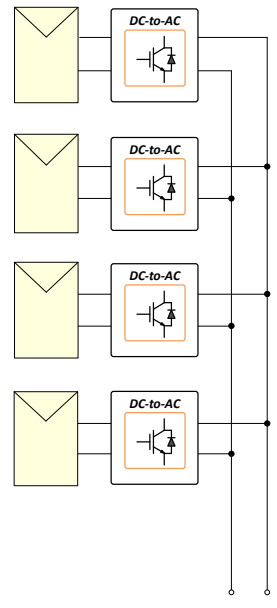

a) MII

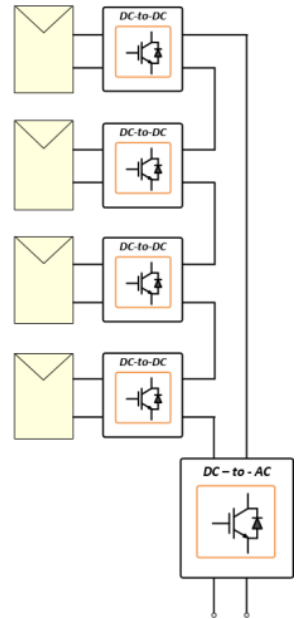

b) MIC in Series

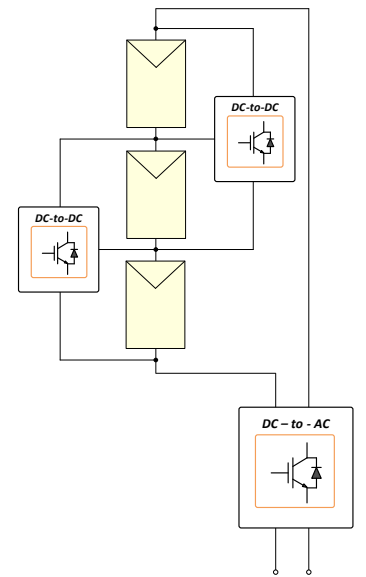

c) DPP

Fig. 5 - Decentralized Grid-Connected PV Inverter Stuctures

\subsubsection{Differential Power Processing (DPP)}

The DPP architecture shown in Fig. (5c), has been proposed in [16] that increases overall conversion efficiency and system scaling. In this architecture [17], the largest part of the power which is common to all PV modules flows to the central inverter directly, while the DC-DC converter process the power mismatch only, which is small compared to full power. DPP process only the differential power due to that PV system achieves high efficiency without insersion losses. Differential converter has higher output power when compared with cascaded dc-dc converter systems and PV strings during MPP mismatch occurs. DPP is more useful than DC optimizer in terms of converter power rating, system efficiency and ease of integration into existing design.

\subsubsection{Sub-Module Architecture}

Sub-module architecture is used to increase the overall system energy capture [18],[19]. In sub-module architecture, PV module is segmented into sub-modules e.g. PV module comprises of solar cells (72 cells), which are segmented into 3 sub-module, each sub-module having 24 cells. Each sub-module employs sub-module distributed MPPTs. These submodules are connected in cascade (for piling up of voltage) to form PV module. This architecture helps to mitigate mismatch losses between sub-modules of same PV module that increases the energy harvest compared converter per module architecure (Distributed architecture). We can employ micro-inverter or micro-converter with each sub-module or we use DPP with sub-module.

\section{DC-DC Topologies}

DC-DC converters finds applications in PV systems as given in Figs. 2(a) \& 2(c) are used to increase energy harvesting. The chopper is an electronics circuit that produce regulated DC output voltage with desired voltage level and higher-power efficiency[20]. The circuit components of choppers are the switches for the control of power flow, inductors and capacitors are used for attenuating the switching ripple in the output power. The choppers produces efficient power conversion between $75 \%$ to $98 \%$. The choppers are classified as non-isolated Fig. (5) and isolated Fig. (6) converters.

The isolation is an electrical or magnetic separation in the middle of input and output terminals of the converters. The Isolated converters are designed by using high frequency transformer and isolated grounds and nonisolated converter does not have dielectric isolation; it shares common ground for input and output terminals. The choppers are operated in two modes. In DCM, the inductor current goes to output, and inductor become fully discharged whereas in CCM; current flows continuously and inductor does not fully discharge. Usually CCM technique is applied for high power levels as it has minimal peak and rms currents, while DCM is needed for low power levels [21]. The power flow is controlled by pulse width modulation with the aid of a closed loop feedback controller. The selection of particular converter depends on the application. 


\subsection{Non-Isolated DC-DC Topologies}

The isolated topologies have leakage inductance issues that causes excess amount of voltage appears across switches. The non-isolated topologies are designed in such way there is no high frequency transformer needed so non-isolated topologies are electrically connected, and input and output terminal shares the common ground. This makes them simple, small in size, easy to control and cheaper. The circuit components of basic topologies are same which are transistor, inductor, diode and capacitor. The buck, boost and buck-boost topologies are formed with different arrangement of these components. The other topologies like SEPIC, Cuk, and Zeta are modified with additional inductor and capacitor.

\subsubsection{Buck Converter}

Buck converter as given in Fig(6a), is used for low load voltages. When PV modules having buck converters are in operation, the output voltage can be stepped-down and output current stepped-up the input. Series-connected modules mitigate the mismatch in current between different modules[22] due to shading. When switch is conducting, diode becomes reversed biased, the current build up and inductor current increases linearly. When switch turned OFF, the diode turned On, the inductor current flows through capacitor, load and diode [23]. It has high input ripple current low output ripple current. The volt-second balance method is used to derive duty ratio D[24]. The DC voltages from PV module is periodically chopped through switching network controlled by duty ratio, resulting pulsated output current is pass through a filter. Hence, the output voltage Vout at the load is the mean value that is smaller than input voltage Vin. The output voltages is determined by duty cycle and input voltage

$$
V_{\text {out }}=D \cdot V_{\text {in }}
$$

In CCM mode, buck converter is used for an efficient power conversion at high power levels as it has minimal peak and rms currents, while in DCM mode, it is used for low power levels [21]. The buck converter finds its applications in in solar battery chargers [25][26], DC water pumping system [27]. The drawback of buck is its restricted operating region due to that MPPT does not reach values near the short circuit current of the PV module [28]. The buck converter is suitable to use when only on a few PV panels have mismatch.

\subsubsection{Boost Converter}

The boost converter is low cost and simple topology. It is suitable when high load voltages are connected to low module voltages. The inductor is connected with PV module before the switching network and capacitor is connected with load as given in fig.(6b). When switch is conduction, the diode become reversed bias, so the capacitor and load resistor will be disconnected. The voltage from DC source is applied through the switch, the inductor starts charging linearly unless the switch turned off. When switch turned off, the current stops flowing through the switch, this compels the diode to become forward bias, and current would now flow through the L, C, diode D and the load [23]. The DC voltages from PV module is periodically chopped through switching network controlled by duty ratio. The volt-second balance method is used to derive duty ratio D [24]. Hence, the output voltage Vout at the load is the mean value that is greater than input voltage. The output voltages of boost topology can be achieved by

$$
V_{\text {out }}=\frac{1}{(1-D)} \cdot V_{\text {in }}
$$

The drawback of boost converter is its restricted operating region due to that MPPT does not reach values near the open circuit voltage of the PV module [28]. For high gain boost converter requires high duty cycle, and this can increase the excess amount of voltage appears across switches.

\subsubsection{Buck-Boost Converter}

The buck-boost (cascaded buck and boost) topology is a bi-directional converter as given in Fig.(6c). When switch conducts, diode become reverse biased that makes an inductor in charging mode and inductor current increases linearly. When switch stops conducting, the polarity of inductor reverses so the stored current forcing the diode to conduct, and current starts flowing to capacitor and load through the diode [30]. The state of inductor defines the CCM and DCM mode of operation of the converter. If inductor current crosses zero level converter operates in DCM otherwise in CCM. The DC voltages from PV module is controlled through the use of duty cycle, resulting pulsated output current is pass through a filter. The volt-second balance method is used to derive duty ratio D [24]. The Buck-mode or Boostmode can be selected through the duty cycle D, boost mode can be chosen by setting the duty cycle higher than 0.5 and if the duty cycle is lower than 0.5 then it operates in buck mode. Thus, the output voltage at the load is the mean value that is greater or lower than input voltage with negative polarity. The output voltages can be achieved by 


$$
V_{\text {out }}=-\frac{D}{(1-D)} \cdot V_{\text {in }}
$$

This topology suitable for PV application because it can be operated from saturation current to cut-off Voltage. In buck-boost topology the switch directly connected with DC source, so it always produce discontinuous input current. This input current contains high ripple that causes significant noise. To make it efficient, converter requires filter that creates complexity in design and increases the cost of converter [31].

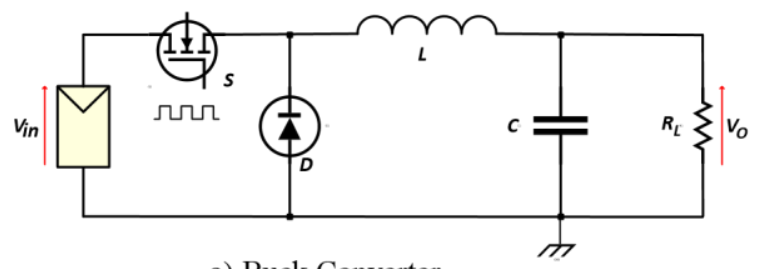

a) Buck Converter

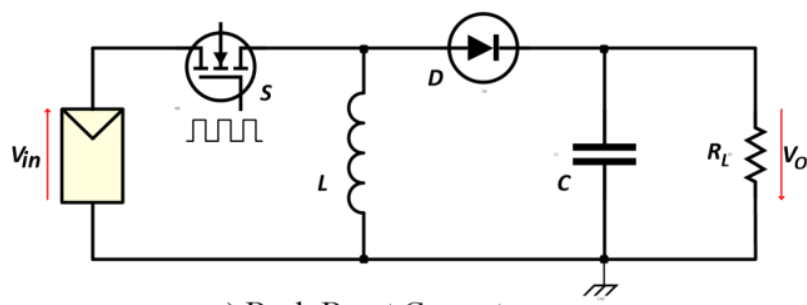

c) Buck-Boost Converter

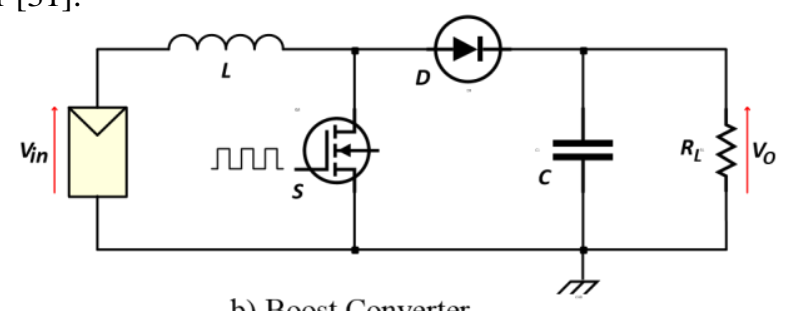

b) Boost Converter

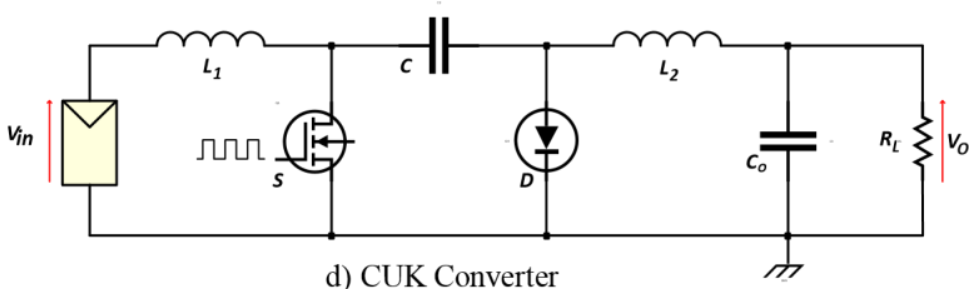

d) CUK Converter

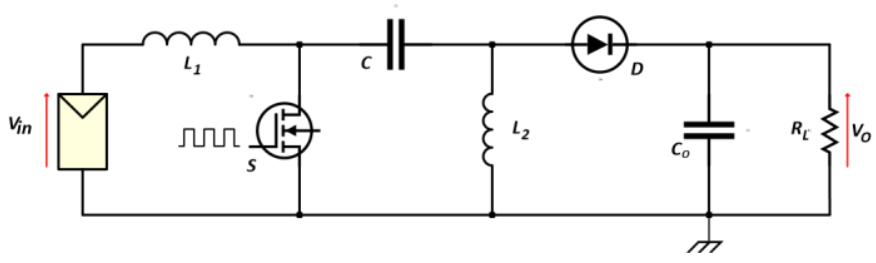

e) SEPIC Converter

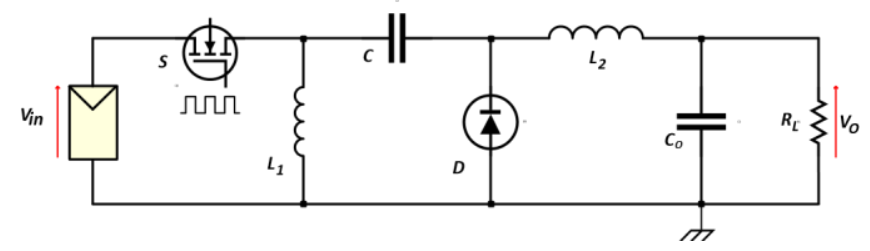

f) Zeta Converter

Fig. 6 - Non-Isolated DC-DC Converters

\subsubsection{CUK Converter}

The Cuk converter as given in Fig. 6(d) is modified dc-dc topology that uses additional capacitor and inductor for energy storage. The input and output polarities of Cuk topology is same as buck-boost converter. The capacitor works as an energy storage element which transfer the power from input to output [23],[32]. The input and output current ripples are passed through capacitors and inductors so they can be filter out without requiring filters. The volt-second balance method is used to derive duty ratio D [24]. The output voltage is controlled through duty ratio D. Higher duty cycle causes negative voltage to raise in the output or lower duty cycle can bring the lower output voltage. Thus, the duty cycle must be kept in between $0<\mathrm{D}<1$ limit. Hence, the output voltage Vout at the load is the mean value that is greater or lower than input voltage with negative polarity. The output voltages of Cuk converter can be achieved by

$$
V_{\text {out }}=-\frac{D}{(1-D)} \cdot V_{\text {in }}
$$

Due to continuous current flows through the inductors, the Ćuk converter operates in CCM, so there is no DCM in Cuk. The advantages of Cuk are the highest efficiency, low input and output ripple current, and low switching losses. Although, Cuk converters have several benefits hence it triggers electrical stress on components, and the outcome of this can be device failure or overheating.

\subsubsection{Single Ended Primary Inductor Converter (SEPIC)}

Buck-boost and Cuk have problems such as polarity reversal of input voltage and electrical stress on the components that causes device failure or overheating. The SEPIC topology given in Fig. 6(e), solves the problems of buck-boost and Cuk converter. In SEPIC, inductor L2 is used to store energy from C1, that causes change in voltage level which reduces the voltage stress from the capacitor $\mathrm{C} 1$. During turn ON time, diode becomes reverse biased due negative polarity of coupling capacitor $\mathrm{C} 1$, the L1 is charged through source and L2 charged through coupling capacitor C1. During turn OFF time of switch, the diode turned ON, coupling capacitor C1 charged through L1 and L2 transfers its energy through C2 to the output. The volt-second balance method is used to derive duty ratio D [24]. Hence, the 
output voltage at the load is the mean value that is higher or lower than input voltage and polarity remains same as input. The output voltage can be achieved by

$$
V_{\text {out }}=\frac{D}{(1-D)} \cdot V_{\text {in }}
$$

The inductor of SEPIC is connected with PV panel due to that reason converter draws ripple free current. That's why the input current of the SEPIC converter is continuous that helps in MPPT operation.

\subsubsection{Zeta Converter}

Zeta topology as given in fig.(6f), can be used when a low ripple and positive output voltage is required. Zeta converter is similar to SEPIC, sometimes known as dual SEPIC [33]. It provides better voltage gain and better efficiency than the regular buck-boost converter. The energy from input source is stored in coupled inductors L1, L2 when switch is conducting. L2 charges the Cout and provides Iout. When switch is not conducting, an inductor L1 discharges current and supply continues to Capacitor C and L2 provides Iout. The volt-second balance method is used to derive duty cycle $\mathrm{D}$ [24]. Hence, the output voltage Vout at the load is mean value that is lower or greater than input voltage Vin with positive polarity. The output voltage can be achieved by

$$
V_{\text {out }}=\frac{D}{(1-D)} \cdot V_{\text {in }}
$$

The advantages of ZETA converter consist of reduced output ripples and easier compensation design. The Zeta converter have some disadvantages, like discontinuous input current, more passive component requirement and it is fourth order converter, which makes the control difficult.

\subsubsection{Hybrid Topologies}

Apart from basic non-isolated topologies and fourth order converters, other novel dc-dc topologies can also be developed. Different techniques can be incorporated such as implementing interleaving and cascading concepts, voltage shifting techniques like switched inductor/capacitor, and using coupled magnetics and voltage multipliers in the circuit can show great deal of variety in dc-dc topologies design and their characteristics. The hybrid structures can split the voltage conversion range into multiple smaller ranges and deliver power in multiple tracks [34].

\subsection{Isolated DC-DC Topologies}

For reliable power transfer with low noise and reduced electromagnetic interference (EMI), electrical isolation is required. The isolation is an electrical or magnetic separation between the output and input terminals of the converters and isolation can be achieved through transformer or coupled inductor [35]. Isolated power converters are categorized as either double-ended or single-ended. The size of power converters become larger when transformer is added in it.

\subsubsection{Flyback Converter}

The flyback converter belong to the family of converters with isolation and the isolation is provided by coupled inductor in its place an AC transformer as given in Fig. 7(a). The Flyback converter is extremely popular and suitable for low power range $(<100 \mathrm{~W})$ applications [36]. The flyback transformer design based on two coupled inductors, the core and transformer phasing. The core controls the flux density for transferring electrical energy from one coil to the other and dot convention describes transformer phasing (output voltages can be either positive or negative) in the primary and secondary coil. The air gap of the coupled inductor used as core to store energy and the turn ratio provides both step down and step up ability. The two switches at both ends controls the energy flow. When switch Q1 conducts, the diode becomes reversed biased, the voltage across the magnetizing inductance causes the current to increase and building up into a primary coil. When switch Q1 switched off, due to flyback moment the polarity of transistor is reversed causing diode to conduct, the stored energy transfer to output through the diode from the secondary coil according to the turn ratio [23]. The current does not flow at the same time in both windings of the flyback transformer. The volt-second balance method is used to derive duty ratio D. The output voltage Vout at the load is mean value that is determined by the transformer turns ratio, the duty cycle and input voltage that is lower or higher than input voltage Vin.

$$
V_{\text {out }}=\frac{N_{s}}{N_{\mathrm{p}}} \frac{D}{(1-D)} \cdot V_{\text {in }}
$$

More energy stored in the transformer results a higher output voltage. If you make duty cycle too high, the flyback will increase output voltage but it will put stress out the transistor. In order to maintain the voltage across the transistor at acceptable levels must keep duty cycle D below 50\%. The flyback conversion has higher output ripple and longer transient response time. 

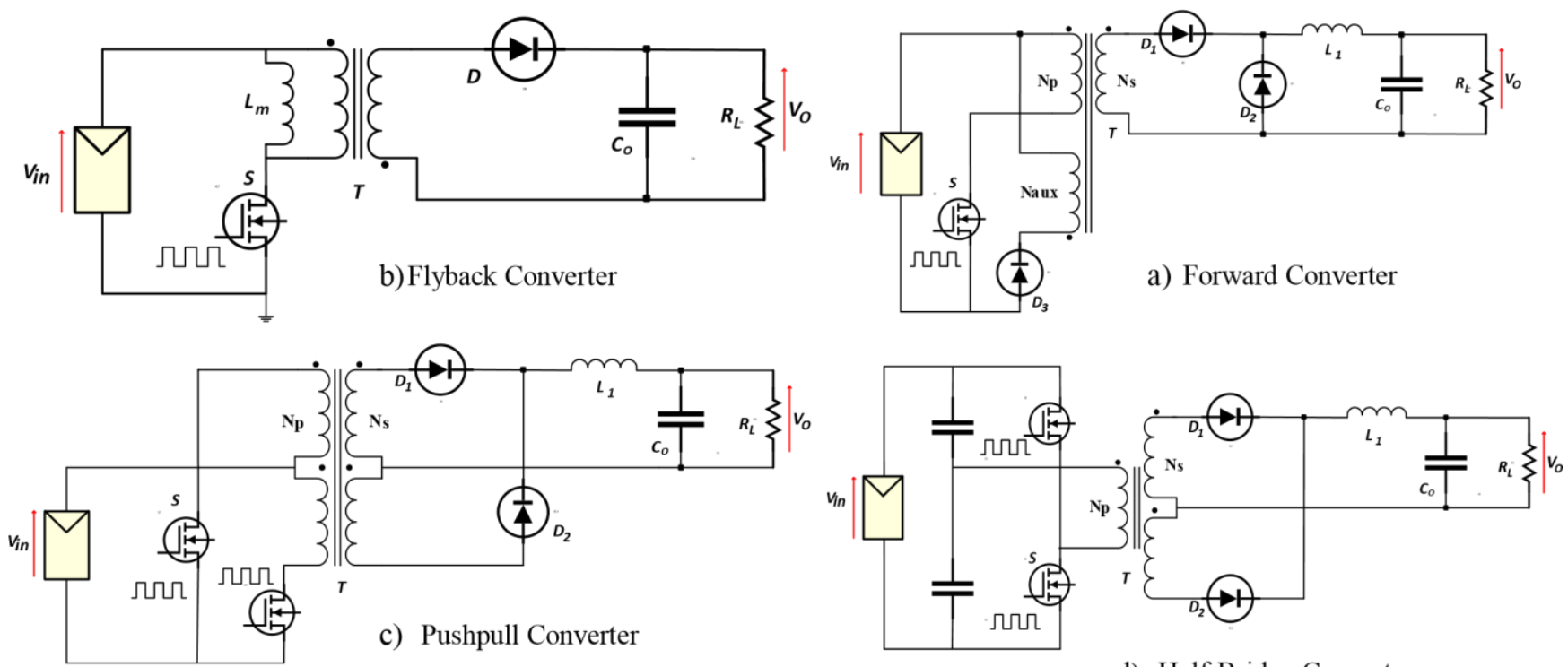

d) Half-Bridge Converter

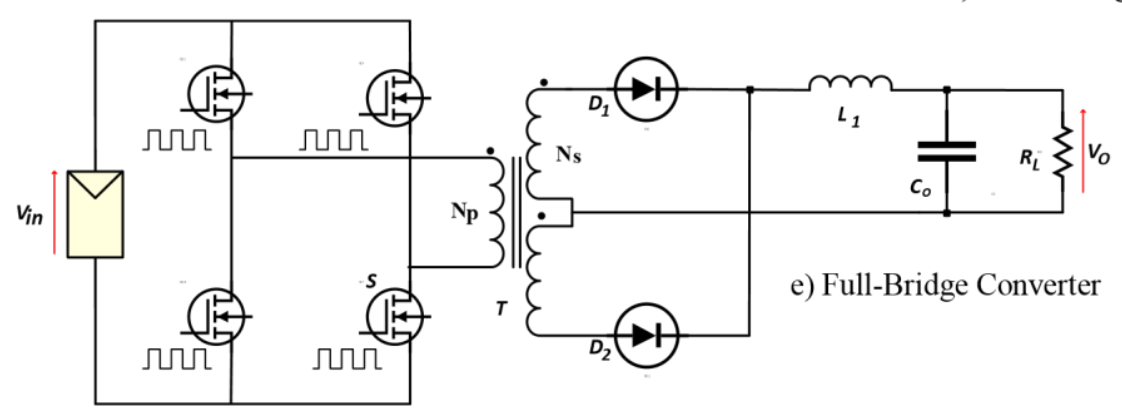

Fig. 7 - Isolated DC-DC Converters

\subsubsection{Forward Converter}

The forward converter belong to the family of converters with isolation which are very useful when connecting to the power lines. Forward converter is given in Fig. 7(b) can produce either higher or lower dc voltage. It is suitable for power range $50 \mathrm{~W}-200 \mathrm{~W}$ applications[36]. When transistor turned ON, the input voltage transferred directly through the transformer will be present on secondary side. The forward current across diode D1 charge the inductor L3 and the output capacitor and delivering energy to the load. When switch is closed, it forces a current across our primary winding which results in DC magnetic bias, that needs a core reset. The forward converter requires a transformer core reset circuit. There are two circuits are used to reset core (demagnetize) either auxiliary winding, or active clamping. Active clamping circuit is connected to the primary side of transformer providing a return path through the diode and allowing a de-magnetizing current to travel once the switch is turned off. If the number of turns of the tertiary and primary is similar, the transformer becomes totally demagnetized before the switch starts conducting, avoiding transformer saturation. The volt-second balance method is used to derive duty ratio D. The output voltage Vout at the load is mean value that is determined by the duty cycle, the transformer turns ratio and input voltage.

$$
V_{\text {out }}=D * \frac{N_{s}}{N_{p}} \cdot V_{\text {in }}
$$

This will turn up voltage stress on the transistor; the duty ratio $D$ needs to be less than $50 \%$ for single ended forward converter. Forward converter generates less ripple, less EMI and has shorter transient response time than flyback.

\subsubsection{Push-Pull Converter}

The push-pull converter as given in Fig. 7(c) is a double ended topology that steps up/down the input voltage level. The push-pull converter have low power ripple, higher efficiency and greater power density. Push-Pull topology is useful for higher power range (100W - 500W) applications [36]. It uses a pair of switches at the primary side of high frequency center tapped transformer that oscillates the current in transformer. In this circuit arrangement both switches are grounded that produces core resetting during each half cycle; hence, no need for active clamp circuit. When switch S1 is turned 
$\mathrm{ON}$, the current flows in half of the primary, increases linearly with time. At some period of time, current approaches to saturation, and the voltages drop to zero that reverses polarities that compels the switch S2 to conduct and switch S1 stops conducting. This self- alternating process will continue, and a bipolar rectangular voltage will be produced at the secondary side of transformer. The volt-second balance method is used to derive duty ratio D. The output voltage Vout at the load is mean value that is determined by the transformer turns ratio, duty cycle and input voltage.

$$
V_{\text {out }}=2 \cdot D * \frac{N_{s}}{N_{p}} \cdot V_{\text {in }}
$$

The maximum duty cycle $D$ must be below $50 \%$. The push-pull converter suffers from high voltage stress. Push pull converters are prone to magnetic flux imbalance in the core, due to mismatching characteristics of two transistors (switches) that causes a transformer saturation problem.

\subsubsection{Half-Bridge Converter}

The half-bridge topology given in Fig. 7(d), is modified version of push-pull converter topology, without center taped primary. It produce higher or lower, positive or negative output voltage level from an input voltage. This topology is suitable for power range up to 500W [36]. Half-bridge converter uses two switches and pair of large equal cascaded capacitors connected across the dc input voltage acts as capacitor voltage divider to produce (1/2 Vin) voltage [20],[23][21][37]. Switches S1 and S2 conducts alternately, divides the input voltage Vin/2 at primary side of the transformer. The energy is transferred to the output when the switches are conducting. The secondary side of half bridge produces a full-wave output that is rectified by diodes and smoothed by L1 and Co [23][21]. The volt-second balance method is used to derive duty ratio D. The output voltage Vout at the load is mean value that is determined by the duty cycle, input voltage and the transformer turns ratio.

$$
V_{\text {out }}=2 \cdot D * \frac{N_{s}}{N_{p}} \cdot V_{\text {in }}
$$

The advantages of Half-bridge converter are better transformer utilization, low power ripples, higher efficiency and greater power density. The drawbacks of half bridge converter are switching losses and unstable capacitor voltages on primary side of transformer.

\subsubsection{Full-Bridge Converter}

Full-bridge topology as given in Fig. 7(e), is an advanced version of half-bridge topology. Full-bridge converter uses four power switches on the primary side instead of two and provides the twice of output power with the same input voltage and current. Full bridge converter can generate higher or lower, negative or positive output voltage level from an input voltage. This is most efficient kind of converter used in high power applications, available power range is 500W and up[21]. The switching operation is done by pairs of diagonal switches (S1-S4 and S2-S3) which are conducts alternatively, input voltage (Vin to -Vin) goes into the primary winding, thus, achieving current reversal on alternate half cycle. At the same time the voltage reflected to the secondary which is proportional to the turn ratio. The current starts flowing in the secondary, gets rectified and smoothed by L and Co. The volt-second balance method is used to derive duty ratio D. The output voltage Vout at the load is mean value that is determined by the duty cycle, the transformer turns ratio and input voltage.

$$
V_{\text {out }}=2 \times V_{\text {in }} \times \frac{N_{s}}{N_{p}} \times D
$$

Full bridge converter have many advantages are reliability, high power density, availability in several standard sizes, and low power losses and wide range of input and output voltage level handling. The full bridge is complex therefore expensive to build due to increase number of switches compared to half-bridge and have highest switching losses. 
Table 2 - Comparison of Isolated DC-DC Converter Topologies [36]

\begin{tabular}{lcccccc}
\hline Topologies & $\begin{array}{c}\text { Power } \\
\text { Range (W) }\end{array}$ & $\begin{array}{c}\text { Transformer } \\
\text { Utilization }\end{array}$ & $\begin{array}{c}\text { No: of } \\
\text { Switch }\end{array}$ & Output Voltages & Voltage Stress & Cost \\
\hline Flyback & $<100 \mathrm{~W}$ & Single-Ended & 1 & Vout $=\frac{D}{1-D} \cdot \frac{N s}{N p} \cdot$ Vin & $>V i+\frac{N s}{N p} \cdot$ Vout & Lowest \\
\hline Forward & $50-200 \mathrm{~W}$ & Single-Ended & 1 & Vout $=D \cdot \frac{N s}{N p} \cdot$ Vin & $>2$ Vin & $>$ Flyback \\
\hline Push-Pull & $100-500 \mathrm{~W}$ & Double-Ended & 2 & Vout $=2 D \cdot \frac{N s}{N p} \cdot$ Vin & $>2$ Vin & $>$ Flyback \\
\hline Half-Bridge & $100-500 \mathrm{~W}$ & Double-Ended & 2 & Vout $=0.5 \mathrm{D} \cdot \frac{\mathrm{Ns}}{\mathrm{Np}} \cdot \mathrm{Vin}$ & $>=0.5$ Vin & $>$ Push-pull \\
\hline Full-Bridge & $>500 \mathrm{~W}$ & Double-Ended & 4 & Vout $=D \cdot \frac{\mathrm{Ns}}{\mathrm{Np}} \cdot \mathrm{Vin}$ & $>=$ Vin & $>$ Half-Bridge \\
\hline
\end{tabular}

\section{Conclusion}

An overview on photovoltaic inverter structures and dc-dc topologies are presented. In the first part of the paper, different conventional power electronic solutions and distributed power electronic solutions are analyzed in terms of cost and efficiency. Decentralized architectures MII, MIC, DPP and sub-module architecture are employed with single PV module and MPPT. Module level MPPT prevent performance issues if one or more panels are shaded. The problems with these solutions are cost and maintenance. Another solution to increase the system energy capture and mitigate mismatch losses PV sub-module architecture. Each sub-module employs sub-module converters with distributed MPPTs. When considering the deployment of micro-inverter with each sub-modules, 3 micro-inverters are required for one PV module. Micro-converters can be empolyed with sub-modules which provides independent submodule MPPT. DPP is an alternative solution that attains high system efficiency with reduced cost by processing a fraction of total power at the expense of increased number of wires and complexity.

In the second part of the paper, various different non-isolated and isolated topologies, their associated features, complexities are reviews and analyzed. The selection of topology is determined by the application, type of power converter and required range of output power. The basic non-isolated topologies buck, boost and buck-boost can be selected if cost, size and simplicity is considered. The designer can choose, buck converter if lower output voltage from input is needed or boost if higher output voltage from input is needed for design. The buck-boost can be converter can be handy if there is need for a converter which produce higher or lower negative output voltage in the same converter. If the selection criteria is performance, the fourth order topologies such as SEPIC, Cuk and Zeta can be good option. These fourth order topologies employed extra inductor and capacitor when compared with second order topologies. The SEPIC and Zeta converters produce positive output voltage and Cuk converter produce higher or lower negative output voltage level efficiently. Isolated topologies known as derived topologies that can be both either single-ended or double-ended and uses transformers for isolation between the input and output terminals. The main considerations for selecting converters are lower ripples, lower conduction losses, lower voltage stress on switches, high conversion efficiencies, low cost of power electronics and high-power density.

\section{Acknowledgement}

The work of this paper was done at Department of Energy Technology Esbjerg Campus, Aalborg University Denmark so I would like to extend my gratitude to Esbjerg Campus for providing me all the facilities that were required. I would like to express special thanks with gratitude to Mr. Dezso Sera, Associate Prof. Energy Technology, Aalborg University Denmark, for guidance and support.

\section{References}

[1] T. Tsoutsos, N. Frantzeskaki, and V. Gekas (2005), Environmental impacts from the solar energy technologies. Energy Policy, 33, 289-296

[2] "RENEWABLES 2019 GLOBAL STATUS REPORT.” [Online]. Available: http://www.ren21.net/gsr-2019/. [Accessed: 19-Feb-2020]

[3] J. D. Van Wyk and F. C. Lee. (2013). On a future for power electronics. IEEE J. Emerg. Sel. Top. Power Electron., $1,59-72$

[4] J. C. Balda and A. Mantooth. (2016). Power-Semiconductor Devices and Components for New Power Converter Developments: A key enabler for ultrahigh efficiency power electronics. IEEE Power Electron. Mag., 3, 53-56

[5] F. Blaabjerg, K. Ma, and D. Zhou. (2012). Power electronics and reliability in renewable energy systems. IEEE International Symposium on Industrial Electronics, 19-30 
[6] "SMA America." [Online]. Available: https://www.sma-america.com/. [Accessed: 19-Feb-2020]

[7] S. B. Kjaer, J. K. Pedersen, and F. Blaabjerg. (2015). A review of single-phase grid-connected inverters for photovoltaic modules. IEEE Transactions on Industry Applications, 41, 1292-1306

[8] F. Iov, M. Ciobotaru, D. Sera, R. Teodorescu, and F. Blaabjerg. (2007). Power electronics and control of renewable energy systems. Proceedings of the International Conference on Power Electronics and Drive Systems.

[9] F. A. Farret (2013). Photovoltaic Power Electronics. Green Energy Technol., 59, 61-109

[10] V. Claudio Crisafulli Coordinator of Tutor Alfio Consoli Alfio Consoli (2007). Analysis and Development of new strategies for solar energy conversion: New systems of integration, topologies and control

[11] P. Mohanty and T. Muneer. (2014). Smart Design of Stand-Alone Solar PV System for Off Grid Electrification Projects. Green Energy and Technology, no. 9783319048154, Springer Verlag, 63-93

[12] S. Islam, A. Woyte, R. Belmans, P. Heskes, P. M. Rooij, and R. Hogedoorn (2006). Cost effective second generation AC-modules: Development and testing aspects. Energy, 31, 1897-1920

[13] K. Ma, Y. Yang, and F. Blaabjerg. (2014). Introduction to renewable energy systems. Studies in Computational Intelligence, 531. Springer, Cham, 3-40

[14] G. R. Walker and P. C. Sernia. (2004). Cascaded DC-DC converter connection of photovoltaic modules. IEEE Trans. Power Electron., 19, pp. 1130-1139

[15] E. Román, R. Alonso, P. Ibañez, S. Elorduizapatarietxe, and D. Goitia. (2006). Intelligent PV module for gridconnected PV systems. IEEE Trans. Ind. Electron., 53, 1066-1073

[16] P. S. Shenoy, K. A. Kim, B. B. Johnson, and P. T. Krein (2013). Differential power processing for increased energy production and reliability of photovoltaic systems. IEEE Trans. Power Electron., 28, 2968-2979

[17] S. Qin, S. T. Cady, A. D. Domínguez-García, and R. C. N. Pilawa-Podgurski. A Distributed Approach to MPPT for PV Sub-Module Differential Power Processing

[18] C. Olalla, D. Clement, M. Rodriguez, and D. Maksimovic. (2013). Architectures and control of submodule integrated dc-dc converters for photovoltaic applications. IEEE Trans. Power Electron., 28, 2980-2997

[19] R. C. N. Pilawa-Podgurski and D. J. Perreault. (2013). Submodule integrated distributed maximum power point tracking for solar photovoltaic applications. IEEE Trans. Power Electron., 28, 2957-2967

[20] N. Mohan, T. Undeland, and W. Robbins. (2009). Power electronics: converters, applications, and design.

[21] A. Pressman and K. Billings. (2009). Switching Power Supply Design

[22] C. Deline, B. Marion, J. Granata, and S. Gonzalez (2011). Performance and Economic Analysis of Distributed Power Electronics in Photovoltaic Systems. Golden, CO (United States)

[23] M. Rashid. (2010). Power electronics handbook: devices, circuits and applications

[24] A. Khaligh, Z. Nie, Y. Lee, and A. Emadi. (2009). Integrated power electronic converters and digital control

[25] M. A. S. Masoum, S. M. M. Badejani, and E. F. Fuchs (2004). Microprocessor-controlled new class of optimal battery chargers for photovoltaic applications. IEEE Trans. Energy Convers., 19, 599-606

[26] M. A. Elgendy, B. Zahawi, and D. J. Atkinson (2012). Assessment of perturb and observe MPPT algorithm implementation techniques for PV pumping applications. IEEE Trans. Sustain. Energy, 3, 21-33

[27] Taufik, A. Oi, M. Anwari, and M. Taufik. (2009). Modeling and simulation of photovoltaic water pumping system. Proceedings - 2009 3rd Asia International Conference on Modelling and Simulation, AMS 2009, 497502

[28] M. H. Taghvaee, M. A. M. Radzi, S. M. Moosavain, H. Hizam, and M. Hamiruce Marhaban. (2013). A current and future study on non-isolated DC-DC converters for photovoltaic applications. Renewable and Sustainable Energy Reviews, 17. Pergamon, 216-227

[29] J. A. Galan et al. Comparative Analysis of Buck-Boost Converters used to obtain I-V Characteristic Curves of Photovoltaic Modules. ieeexplore.ieee.org

[30] T. M. Augustin McEvoy and L. Castaner. (2012). Practical Handbook of Photovoltaics (Second Edition), no. c. Academic Press

[31] E. Durán, J. M. Andújar, F. Segura, and A. J. Barragán (2011). A high-flexibility DC load for fuel cell and solar arrays power sources based on DC-DC converters. Appl. Energy, 88, 1690-1702

[32] V. Suresh Kumar, K. R. Ramela, and A. F. Zobaa. (2013) A cuk converter to improve the ride-through capability of low power adjustable speed drives for voltage sag and swell. Int. Rev. Electr. Eng., 8, 1302-1310

[33] J. Jozwik. (1989). M. K.-I. T. on Industrial. Dual sepic PWM switching-mode DC/DC power converter. ieexplore.ieee.org

[34] M. Chen, K. Afridi (2016), S. C.-I. T.Multitrack power conversion architecture. ieeexplore.ieee.org

[35] M. Forouzesh, Y. Siwakoti (2017), S. G.P. Electronics. Step-up DC-DC converters: a comprehensive review of voltage-boosting techniques, topologies, and applications. ieeexplore.ieee.org

[36] Y. Fu, Z. Li, W. Ng, and J. Sin (2014). Integrated Power Devices and TCAD Simulation. [37] N. Mohan (2012). Electric power systems: a first course 